\title{
Radiação solar e temperatura do ar em ambiente protegido
}

Perila Maciel Rebouças ${ }^{1}$

Itala Farias Dias ${ }^{2}$

Melânia de Araújo Alves ${ }^{3}$

José Antonio Delfino Barbosa Filho ${ }^{4}$

\section{Resumo}

O cultivo realizado em casa de vegetação é uma das tecnologias que têm contribuído para a modernização da agricultura, atenuando os danos causados pelas adversidades climáticas e, consequentemente, vem colaborando com o aumento da produção de alimentos no Brasil e no mundo. Diante disso, esta revisão tem o objetivo de descrever o comportamento das variáveis ambientais, radiação solar e temperatura do ar em um ambiente protegido com cobertura plástica, com enfoque nos aspectos climáticos envolvidos, sob as culturas agrícolas.

Palavras-chave: Cultivo protegido. Agricultura. Variáveis climáticas.

\section{Introdução}

O uso do plástico na cobertura de casas de vegetação surgiu como alternativa na proteção de hortaliças e flores, diante das adversidades climáticas. Vida et al. (2004) sintetizaram algumas vantagens do cultivo em estufas ou ambientes protegidos, como: o aumento de produtividade, coIheita na entressafra, precocidade da colheita, maior qualidade dos produtos, melhor controle das condições ambientais, controle mais eficiente de pragas e doenças, melhor aproveitamento no uso dos recursos, minimização do risco e maximização da competitividade mercadológica do produtor. De acordo com Beltrão et al. (2002), o cultivo em estufa possibilita determinado controle das condições edafoclimáticas, tais como: temperatura, umidade do ar, radiação luminosa, solo, vento e composição atmosférica, e implica a utilização de instrumentação e dispositivos de controle apropriados (ROMANINI et al., 2010).

No mundo, parte significativa da pesquisa agrícola e da produção de algumas plantas ornamentais e hortaliças é realizada em casas de vegetação ou teladas (casas de plástico não climatizadas), na maioria dos casos, sem controle do ambiente (luz, irradiação solar global, irradiação infravermelha e calórica, umidade relativa e temperatura do ar).

Estima-se que, nas últimas décadas, o cultivo em ambiente protegido no Brasil apresentou crescimento significativo, principalmente para a produção de hortaliças e flores que possuem elevado

$1 \quad$ Universidade Federal do Ceará, Mestranda em Engenharia Agrícola. Fortaleza, Ceará, Brasil. perilamaciel06@gmail.com. (085) 3366-9754. Av. Mister Hull, Campus do PICI Bloco 804, Fortaleza, Ceará, CEP 60450-760, Caixa Postal 12.168.

2 Universidade Federal do Ceará, Mestre em Engenharia de Pesca. Fortaleza, Ceará, Brasil. italafarias@gmail.com. (085) 33669754. Av. Mister Hull, Campus do PICl Bloco 804, Fortaleza, Ceará, CEP 60450-760, Caixa Postal 12.168.

3 Universidade Federal do Ceará, Mestranda em Zooctenia. Fortaleza, Ceará, Brasil. melaraujo@zootecnista.com.br. (085) 33669754. Av. Mister Hull, Campus do PICl Bloco 804, Fortaleza, Ceará, CEP 60450-760, Caixa Postal 12.168.

$4 \quad$ Universidade Federal do Ceará, Professor Doutor do Departamento de Eng. Agrícola. Fortaleza, Ceará, Brasil. zkdelfino@gmail.com. (085) 3366-9754. Av. Mister Hull, Campus do PICI Bloco 804, Fortaleza, Ceará, CEP 60450-760, Caixa Postal 12.168. 
valor econômico (SILVA et al., 2003; REIS et al., 2012). Em 1995, no Brasil havia 1000 ha de estufas utilizadas para o cultivo de plantas ornamentais e hortaliças de várias espécies de plantas e, na área científica, cerca de 40 ha de casas de vegetação, representando 35,29\% de casas de vidro, $37,81 \%$ de plástico (polietileno) e $21,84 \%$ do tipo guarda-chuva (OLIVEIRA, 1995; BELTRÃO et al., 2002). Vale ressaltar que, durante esta mesma década de 90 , as estimativas globais indicavam uma área de 716 mil hectares com estufas. Já em 2010, foram 3,7 milhões de hectares de plantas cultivadas também em casa de vegetação, das quais a maior parte era constituída de hortaliças. Nesse tipo de plantio, a China representa o país que concentrou e ainda concentra a maior área de cultivos protegidos no mundo em estufas. Vale ressaltar também que a produtividade das hortaliças cultivadas em estufas na China é o dobro da realizada em área sem cobertura. Apesar de a área de estufas ser bastante inferior à dos países que lideram o ranking de cultivo protegido no mundo, o Brasil lidera a posição quando comparado com os países da América do Sul. Atualmente, segundo o Comitê Brasileiro de Desenvolvimento e Aplicação de Plásticos na Agricultura (COBAPLA), o Brasil tem 22 mil hectares de cultivo protegido (túneis e estufas), nos quais são produzidas hortaliças, flores e viveiros. Metade dessa área, cerca de 11 mil hectares, situam-se no estado de São Paulo. Portanto, a adoção do cultivo protegido se expandiu rapidamente pelo mundo (SILVA et al., 2014).

Sabe-se que existe uma forte relação da temperatura do ar com a incidência de radiação solar dentro de uma casa de vegetação. Nesse sentido, Farias et al. (1993), ao observarem o efeito da cobertura plástica sobre a temperatura e a umidade relativa do ar, verificaram que essas variáveis climáticas estão intimamente relacionadas com as condições atmosféricas do ambiente externo. Assim, conforme os autores, em dias chuvosos ou nublados ou de ventos fortes e frios, o efeito da nebulização sobre a redução da temperatura, no interior de ambientes protegidos, será menor que em dias claros de céu aberto e de alta incidência de radiação solar.

Além disso, Farias et al. (1993) afirmaram também que a temperatura do ar no interior na estufa depende dos processos de incidência da radiação solar, reflexão e reirradiação pelos objetos no interior do ambiente protegido, condução das paredes, renovação do ar e troca de calor com o solo. Valandro et al.(2007) ressaltaram ainda que a temperatura do ar no interior da estufa está relacionada, principalmente, com o balanço de energia, dependente, portanto, de fatores tais como a transmissividade do plástico, o ângulo de incidência da radiação solar sobre a cobertura e a renovação do ar do seu interior.

Reis et al. (2012) também enfatizam a conexão existente destas duas variáveis climáticas, temperatura e radiação solar, ao afirmarem que o cultivo agrícola em estufas permite proteção às plantas contra temperaturas elevadas e alta intensidade de radiação solar, durante todo o seu crescimento. Conforme os autores, a luz tem influência complexa no crescimento, no desenvolvimento e na produção das culturas e, devido à absorção e reflexão do material da cobertura plástica, a densidade de fluxo da radiação solar global, no interior do ambiente protegido, é menor que a observada externamente. $\mathrm{O}$ aumento da irradiância pode elevar a produção de fotoassimilados e sua disponibilidade para o crescimento da planta e produção de frutos. Entretanto, quando a radiação solar é excessivamente elevada, pode haver aumento na taxa transpiratória da planta, resultando em fechamento estomático e em diminuição da fotossíntese (ANDRIOLO, 2000). Al-Jamal (1994) acrescenta ainda que a temperatura do ar no interior do ambiente protegido, ou seja, na casa de vegetação, é também determinada pela hora do dia e da distribuição da radiação solar durante o dia.

No Brasil, tem crescido o uso de tela plástica na agricultura com o objetivo de atenuar a densidade de fluxo de radiação solar, possibilitando o cultivo, principalmente, de olerícolas, em épocas 
com alta disponibilidade energética. A caracterização da atenuação da radiação solar é importante, pois afeta os outros componentes do balanço de energia, como os fluxos de calor sensível e latente, além do processo fotossintético (PEZZOPANE et al., 2004). As malhas termorrefletoras, que são metalizadas com alumínio em ambas as faces, promovem a conservação de energia no ambiente e reflexão de parte da energia solar, resultando em menores temperaturas no verão e maiores temperaturas no inverno. Por serem retorcidos, os fios das malhas promovem a difusão da luz, o que aumenta a eficiência de captura de energia pelas plantas e, consequentemente, a eficiência da fotossíntese (LEITE et al., 2008).

Essa revisão de literatura tem o objetivo de destacar os conhecimentos sobre o comportamento das variáveis climáticas, radiação solar e temperatura do ar em ambiente protegido com cobertura plástica, bem como o de relatar os principais aspectos climáticos envolvidos sob as culturas agrícolas.

\section{Radiação solar em ambiente protegido}

Considera-se radiação solar o fluxo de energia proveniente do Sol, que emite uma densidade de fluxo de cerca de 6,33 x $107 \mathrm{Wm}^{2}$, na forma de ondas eletromagnéticas. Ao incidir no topo da atmosfera, a radiação solar se propaga até atingir a superfície terrestre, passando durante esse percurso pelos processos de reflexão, absorção e espalhamento, que não são suficientes para reter todo o espectro da radiação solar. A parcela da radiação solar que atinge a superfície terrestre, que aparentemente não sofre interação direta, é denominada de irradiação solar direta, enquanto a que atinge a superfície após sofrer o processo de espalhamento é denominado de irradiação solar difusa (GOMES, 2006). E, quando um raio luminoso atinge a superfície do material de cobertura de uma estufa, a sua energia se divide em três frações: uma parte é refletida, outra é absorvida e uma terceira é transmitida. A parte refletida é perdida para a atmosfera e a parte absorvida irá aquecer o material de cobertura, o qual, posteriormente, emitirá a energia absorvida nas duas direções. Por isso, considera-se que somente a metade, aproximadamente, da energia solar absorvida pelo material será recuperada pela cultura. A parte transmitida passa diretamente para o interior do ambiente protegido onde está a cultura. Nesse ambiente, uma competição pela energia luminosa se estabelece entre as plantas e todos os materiais existentes, como as estruturas de sustentação e condução das plantas, além do solo. Este último é um grande absorvedor de energia luminosa, principalmente pelo calor latente de vaporização da água que está contida em seu interior (ANDRIOLO,1999). À vista disso, conforme Monteith e Unsworth (2008), estudos microclimáticos realizados em ambiente protegido necessitam focar na radiação solar plena e no saldo de radiação, haja vista que esses elementos determinam a disponibilidade de energia para processos como evapotranspiração, aquecimento do ar e do solo e fotossíntese.

Gonçalves (2007), em experimento com a videira 'Niagara Rosada', observou redução na radiação solar de 42 e $60 \%$ pela utilização de tela plástica com 30 e $70 \%$ de sombreamento, respectivamente, em relação ao tratamento a pleno sol. Ferreira et al. (2004), em trabalho realizado em vinhedos de 'Cabernet Sauvignon', observaram diminuição do nível de radiação solar e aumento das temperaturas máximas quando utilizaram cobertura de polietileno de baixa densidade com aditivado anti-ultravioleta, em relação ao cultivo a céu aberto. Em trabalho realizado sob cobertura plástica trançada de polipropileno, com tratamentos contra raios ultravioleta, Cardoso et al. (2008) obtiveram redução de 33\% da disponibilidade de radiação fotossinteticamente ativa incidente sobre o dossel, durante o experimento com a cultivar Moscato Giallo. Mota et al. (2008), utilizando o mesmo tipo 
de cobertura plástica, concluíram que ela não interferiu na fenologia, na qualidade das gemas vegetativas e reprodutivas, e nas dimensões e massa fresca de cachos e bagas da cultivar Cabernet Sauvignon. Todavia, o uso da cobertura promoveu maior crescimento vegetativo nos ramos principais (ROBERTO et al., 2011).

Assim, a radiação solar possui importância decisiva em todos os processos vitais das plantas, tais como a fotossíntese, transpiração, fotoperiodismo, crescimento dos tecidos e floração, entre outras (KITTAS et al., 1999; BECKMANN et al., 2006; GUISELINI et al., 2010). Portanto, a escolha do material de cobertura de uma casa de vegetação é fator decisivo para a manutenção e desenvolvimento da cultura, podendo alterar a radiação solar transmitida ao interior da estufa, beneficiando as plantas de acordo com suas exigências (CUNHA; ESCOBEDO, 2003; GUISELINI et al.,2004).

\section{Influência da cobertura plástica na incidência de radiação solar}

A reflexão e a absorção promovida pela cobertura plástica diminuem a incidência de radiação solar no interior do ambiente protegido. Essa redução é variável em função do ângulo de incidência dos raios solares e da transmitância do filme plástico, ou seja, do tipo, idade e cor do filme. Conhecer as características de transmissividade da radiação de um material de cobertura é importante para avaliar os benefícios potenciais dos diferentes materiais, pois é conhecido que pequenas diferenças na transmitância de um material à radiação solar podem ter efeito significativo no crescimento e desenvolvimento da cultura (GUISELINI, 2002). Para análise da relação da radiação solar com o desempenho da cultura, sabendo-se que a radiação excita as moléculas da clorofila, necessita-se de estudos da taxa fotossintética e condutância estomatal, além da modelagem de crescimento (FONSECA et al., 2006), da estimativa da fotossíntese (STEIDLE NETO et al., 2006) e do acúmulo de biomassa (MOREIRA et al., 2005).

Mundialmente, o material plástico mais empregado, nos dias atuais, na agricultura, é o polietileno de baixa densidade (PEBD). É um material que não só apresenta boa transparência à radiação solar como também deixa atravessar, em média, 70 a 80\%, dessa radiação, podendo este percentual atingir, no máximo, 95\% (FERREIRA, 2003). Trata-se de uma lona plástica trançada de polipropileno translúcido, impermeabilizada com polietileno de baixa densidade, aditivada com filtro anti-ultravioleta que se apresenta em diversas espessuras (150, 160, 170 $\mu \mathrm{m})$. Esse material apresenta, como já informado, boa transparência à radiação solar, deixando passar, em média, 70 a 90\% da radiação de onda curta incidente e até $80 \%$ da radiação de onda longa. Entretanto, a utilização da cobertura plástica implica o aumento do custo de investimento para a implantação e manutenção do plástico, sendo a vida útil do plástico de três a quatro anos (ROBERTO et al., 2011).

Outras vantagens da utilização da cobertura plástica referem-se à proteção das plantas contra os danos causados por granizo, as perdas por geadas tardias, o maior teor de sólidos solúveis totais e menor acidez titulável das bagas (ROBERTO et al., 2011). Alguns resultados preliminares já apontaram um grande potencial no uso dessa tecnologia em alguns polos de produção de uva de mesa e para processamento, dentre eles, Rio Grande do Sul, Santa Catarina, Vale do São Francisco e Paraná. Essa tecnologia pode, inclusive, ser empregada em diversos sistemas de condução das videiras, como latada e manjedoura (MOTA et al., 2008; CHAVARRIA et al., 2009).

No entanto, Ferreira (2003) constatou que, mesmo utilizando-se polietileno de baixa densidade, aditivado com anti-ultravioleta e com espessura de $150 \mu \mathrm{m}$, os valores de temperatura do ar no ambiente parcialmente modificado foram mais elevados, em comparação aos valores obtidos em 
ambiente a céu aberto; e a transmissividade de radiação solar para o interior da estufa foi de $85,5 \%$, o que diminui a produtividade para algumas espécies do cultivo estudado.

Mas, segundo Seeman (1979), durante o dia, se o saldo de radiação for positivo, a superfície do solo aquece a parcela de ar próxima a ela, gerando um processo convectivo. Dentro de estufas, esse processo é interrompido pela cobertura plástica, que impede a ascensão do ar quente e provoca a elevação da temperatura, o que afeta o balanço de energia, dependendo do tipo de cobertura, do ângulo de incidência da radiação solar, do tipo de solo e, principalmente, do tamanho da estufa e seu volume.

Além disso, a luminosidade é atenuada de forma diferenciada, conforme o tipo do material de cobertura (SENTELHAS; SANTOS, 1995). A luz, fração visível da energia solar, que contém a irradiância fotossinteticamente ativa (IFA) compreendida na faixa de 390 a 700 nm, tem importância fundamental em vários processos que ocorrem na planta, especialmente a fotossíntese. Portanto, o telhado e as laterais da casa de vegetação e/ou telados devem estar sempre limpos, sem poeira impregnada, a qual reduz substancialmente a luminosidade no interior da casa, causando problemas sérios no crescimento e no desenvolvimento vegetal, reduzindo a fotossíntese e promovendo estiolamento das plantas (BELTRÃO et al., 2002). O fluxo de radiação transmitido em uma casa de vegetação também é afetado por fatores extrínsecos, além da poeira, tais como: condensação da umidade atmosférica, envelhecimento do material plástico e o design da estufa (estruturas de sustentação) (CABRERA et al., 2009).

Em experimento realizado em ambientes protegidos cultivados com gérbera, em Piracicaba, SP, avaliando diferentes tipos de cobertura, Guiselini et al. (2004) verificaram que as malhas termorrefletora e preta, quando associadas ao plástico leitoso, apresentaram transmitâncias médias da radiação solar, da ordem de 11 e 7\%. A associação com malha preta, por atenuar mais a radiação solar, resultou em maior altura de planta e menor emissão de botões florais de gérbera. Nesse experimento, os autores notaram que o uso da malha preta não foi satisfatório, se comparado ao uso da termorrefletora.

As alterações microclimáticas no interior de casas de vegetação, provocadas pela utilização do polietileno, modificando a temperatura do ar, a umidade relativa do ar e a radiação solar, influenciam no desenvolvimento e no crescimento vegetal, e estes são dependentes da intensidade, qualidade e duração da radiação solar (SCARANARI et al., 2008). Essas alterações minimizam a incidência de doenças fúngicas e a substancial aplicação de defensivos (CHAVARRIA et al., 2007) e interferem na fisiologia das plantas (CHAVARRIA et al., 2009).

\section{Temperatura do ar em ambiente protegido}

Como já enfatizado, as variáveis meteorológicas no interior de estufas apresentam comprovada variabilidade espacial, influenciando no desenvolvimento das culturas por meio de efeitos na transpiração e na fotossíntese. 0 controle e o monitoramento das outras variáveis meteorológicas, principalmente a umidade e a temperatura do ar, são fatores importantes, podendo interferir de forma benéfica ou maléfica no desenvolvimento da planta. Assim, controlar esses fatores é de suma importância e o uso do ambiente protegido vem somar a essa busca por melhores resultados (SILVA et al., 2003; SANTOS et al., 2010)

Zhang et al. (2010) constataram que a variabilidade dos fatores climáticos no interior de uma casa de vegetação não está relacionada somente à radiação solar, mas também às características 
relacionadas ao movimento de convecção das massas de ar nas extremidades do ambiente protegido, assim como a dinâmica da pressão de vapor do ar que ocorre devido a uma diferença de temperatura interna e externa. Zhang et al. (2010) destacam também que a variabilidade espacial de dados climatológicos aplicada a cultivos em ambiente protegido tem como função a compreensão e entendimento dos fatores relacionados à evapotranspiração do vegetal, e esse processo, por sua vez, está ligado ao desenvolvimento das plantas, visto que interfere na absorção de nutrientes e água pelas culturas.

A temperatura média diária no interior da estufa é sempre mais elevada que no exterior, e as diferenças variam em torno de 0,5 a $9,0^{\circ} \mathrm{C}$. As maiores diferenças ocorrem das 12 às 16 horas, horários de temperaturas do ar mais elevadas (FARIAS et al., 1993). Já a temperatura mínima do ar no interior é igual ou ligeiramente superior à observada externamente (VILLELE, 1993; BURIOL et al., 1993; HELDWEIN et al., 2001). Por sua vez, a umidade relativa do ar, durante o período diurno, com o aumento da temperatura, diminui com mais intensidade no interior da estufa do que no ambiente externo, tornando-se geralmente inferior à verificada externamente das 8 às $14 \mathrm{~h}$. Porém, durante o final da tarde $\mathrm{e}$ à noite, aumenta rapidamente. Isso se deve à queda da temperatura verificada neste período no interior da estufa, principalmente, e à retenção do ar úmido pela cobertura plástica (BURIOL et al., 2000).

Vale salientar que o conteúdo de vapor de água do ar no interior da estufa é muito influenciado pela evapotranspiração, pois, em função de se manter o solo e/ou o substrato desse ambiente permanentemente próximo à capacidade de campo por meio de irrigação, a demanda evaporativa do ar é plenamente atendida. Assim, o elevado conteúdo de vapor d'água no ar do interior da estufa origina uma alta pressão parcial de vapor mesmo quando a umidade relativa do ar é baixa (FARIAS et al., 1993; BURIOL et al., 2000). Assim mesmo, os totais de evapotranspiração no interior das estufas são menores do que no exterior, decorrente, principalmente, da atenuação do fluxo de radiação solar e da velocidade do vento pelo filme plástico. No entanto, a temperatura e a umidade relativa do ar, em alguns momentos, podem atingir valores maiores no interior do ambiente protegido, com estreita dependência das condições meteorológicas. Em geral, a evapotranspiração no interior do ambiente protegido fica em torno de 60-80\% da verificada no exterior (VÁSQUEZ et al., 2005).

A temperatura dentro de uma estufa também pode variar ao longo do dia; para manter uma temperatura adequada no interior da estufa, é fundamental o acúmulo de energia durante o dia e sua manutenção durante a noite, contudo, nem sempre isso ocorre. Segundo Romanini et al. (2010), essas diferenças de temperatura ao longo do dia podem resultar em um desenvolvimento irregular das plantas no interior da casa de vegetação.

No estudo de Silva et al. (2003) sobre a temperatura do ar em ambiente protegido no cultivo de hortaliças, as estufas estudadas cobertas com filme de polietileno tiveram os valores da temperatura máxima do ar acentuadamente alterados. A nebulosidade determinou o comportamento das temperaturas internas. Conforme os autores, recomenda-se abrir as laterais quando a temperatura interna da estufa alcançar o limite fisiológico da cultura, observando sempre que a temperatura interna foi superior à externa, na ordem de 10 a 25\%. A estufa coberta com filme leitoso, com 150 micra de espessura, foi a que apresentou melhores resultados, ainda conforme os autores, para as condições da região, município de Quatro Barras, Paraná, visto que sua tendência de linearidade no aumento da temperatura não foi limitante para a sua implementação.

Algumas características construtivas também podem influenciar a temperatura do ar dentro de uma estufa, tais como a altura do pé direito, sentido e incidência dos ventos, tipo e cor da cobertura, material utilizado nas laterais, se há janelas ou cortinas, tipo de solo, entre outros fatores (SANTOS et al., 2010), pois a baixa eficiência dos sistemas de ventilação pode originar condições de umidade 
inadequadas em algumas regiões. Alta umidade pode ser observada durante os períodos de nublado e durante a noite. Durante o verão, as condições de umidade podem ser muito baixas. Muitos produtores dão prioridade ao controle da temperatura, esquecendo que o manejo da ventilação deve ser feito levando em consideração a importância da interação entre as duas variáveis (BAILLE, 2012). Como exemplo, Oliveira et al. (2012), ao compararem a temperatura do ar observada em diferentes ambientes cobertos com telas - termo refletora, sombreamento branca, sombreamento preta e cromatinete difusor - com a observada em campo aberto durante o cultivo de tomateiro, relataram que nos ambientes protegidos a temperatura máxima diária foi superior à de campo aberto, e a maior diferença foi observada sob a tela de sombreamento branca, em $1,6^{\circ} \mathrm{C}$. Além disso, em média, em todos os ambientes, as temperaturas apresentaram-se dentro da faixa considerada ideal para o desenvolvimento do tomateiro, já que a temperatura mínima foi um pouco menor do que a observada no cultivo a campo aberto, e a maior transmitância da radiação solar global por meio da tela de sombreamento branca foi determinante para temperaturas mais elevadas nesse ambiente.

\section{Conclusões}

O comportamento das variáveis ambientais, temperatura do ar e radiação solar, pode servir de apoio para a avaliação do tipo de estufa ou casa de vegetação a ser inserida em uma cultura agrícola. Além disso, essas variáveis não devem ser observadas isoladamente, pois elas possuem uma forte relação entre si e entre as demais variáveis climáticas. Contudo, dada a importância atual dos ambientes protegidos para agricultores e pesquisadores, é de fundamental importância o conhecimento da radiação solar e suas relevâncias e modificações climáticas para um melhor planejamento do cultivo.

\section{Solar radiation and air temperature in greenhouse}

\section{Abstract}

The culture held in a greenhouse is one of the technologies that have contributed to the modernization of agriculture, mitigating the damage caused by adverse weather, and consequently has been collaborating with the increase of food production in Brazil and worldwide. Therefore, this review aims to describe the behavior of the environmental variables, solar radiation and air temperature in a protected plastic cover, with a focus on climatic aspects involved in the crop environment.

Keywords: Protected cultivation. Agriculture. Climate variables.

\section{Referências}

AL-JAMAL, K. Greenhouse cooling in hot countries. Energy, v.19, n.11, p. 1187-1192, 1994.

ANDRIOLO, J. L. Fisiologia das culturas protegidas. Santa Maria: UFSM. 1999. 142p.

ANDRIOLO, J. L. Fisiologia da produção de hortaliças em ambiente protegido. Horticultura Brasileira, v.18, p.26-33, Suplemento, 2000.

BAILLE, A. Overview of greenhouse climate control in the mediterranean regions. Cahiers Options Méditerranéennes, v.31, p.59-76, 2012. 
BECKMANN, M. Z.; DUARTE, G.; BURCK, R.; PAULA, V. A. Radiação solar em ambiente protegido cultivado com tomateiro nas estações verão-outono do Rio Grande do Sul. Ciência Rural, v.36, n.1, p.86-92, 2006.

BELTRÃO, N. E. de M.; FIDELES FILHO, J.; FIGUEIRÊDO, I. C. M. Uso adequado de casa-de-vegetação e de telados na experimentação agrícola. Revista Brasileira de Engenharia Agrícola e Ambiental, v.6, n.3, p.547-552, 2002.

BURIOL, G. A.; SCHNEIDER, F. M.; ESTEFANEL, V.; ANDRIOLO, J. L.; MEDEIROS, P. S. L. Modificação na temperatura mínima do ar causado por estufas de polietileno transparente de baixa densidade. Revista Brasileira de Agrometeorologia, v.1, p.43-49, 1993.

BURIOL, G. A.; ESTEFANEL, V.; ANDRIOLO, J.L.; MATZENAUER, R.; TAZZO, I.F. Disponibilidade de radiação solar para o cultivo do tomateiro durante o inverno no Estado do Rio Grande do Sul. Pesquisa Agropecuária Gaúcha, v.6, n.1, p.113-120, 2000.

CABRERA, F. J; BAILLE, A.; LÓPEZ, J. C.; GONZÁLEZ-REAL, M. M.; PÉREZ-PARRA, J. Effects of cover diffusive properties on the components of greenhouse solar radiation. Biosystems Engineering, v.103, p.344-356, 2009.

CARDOSO, L. S.; BERGAMASCHI, H.; COMIRAM, F.; CHAVARRIA, G.; MARODIN, G. A. B.; DALMAGO, G. A.; SANTOS, H. P.; MANDELLI, F. Alterações micrometeorológicas em vinhedos pelo uso de coberturas de plástico. Pesquisa Agropecuária Brasileira, v.43, p.441-447, 2008.

CUNHA, A. R.; ESCOBEDO, J. F. Alterações micrometeorológicas causadas pela estufa plástica e seus efeitos no crescimento e produção da cultura de pimentão. Revista Brasileira de Agrometeorologia, v.11, p.15-26, 2003.

CHAVARRIA, G.; CARDOSO, L. S.; BERGAMASCHI, H.; SANTOS, H. P.; MANDELLI, F.; MARODIN, G. A. B. Microclima de vinhedos sob cultivo protegido. Ciência Rural, v.19, n.7, p.2.029-2.034, 2009.

CHAVARRIA, G.; SANTOS, H. P.; SÔNEGO, O. R.; MARODIN, G. A. B.; BERGAMASCHI, H.; CARDOSO, L. S. Incidência de doenças e necessidade de controle em cultivo protegido de videira. Revista Brasileira de Fruticultura, v.29, n.3, p.477-482, 2007.

FARIAS, J. R. B.; BERGAMASCHI, H.; MARTINS, S. R.; BERLATO, M. A. Efeito da cobertura plástica de estufa sobre a radiação solar. Revista Brasileira de Agrometeorologia, v.1, n.1, p.31-6, 1993.

FERREIRA, M. A. Influência da modificação parcial do ambiente por cobertura plástica, no microclima e em parâmetros fitotécnicos de vinhedo de 'cabernet sauvignon'. 2003. 73 p. Dissertação (Mestrado). Instituto Agronômico, Campinas.

FERREIRA, M. A.; PEDRO JÚNIOR, M. J.; SANTOS, A. O.; HERNANDES, J. L. Modificação parcial do ambiente de cultivo da videira 'Cabernet Sauvignon' sobre diferentes porta-enxertos: efeito sobre a produção e o teor de sólidos solúveis. Bragantia, v.63, p.439-445, 2004.

FONSECA, E. L. da; SILVEIRA, V. C. P.; SALOMONI, E. Eficiência de conversão da radiação fotossinteticamente ativa incidente em biomassa aérea da vegetação campestre natural no bioma Campos 
Sulinos do Brasil. Ciência Rural, v.36, n.2, p.656-659, 2006.

GONÇALVES, A. L. Efeito do sombreamento artificial contínuo no microclima, crescimento e produção da videira 'Niagara rosada'. 2007. 62 p. Dissertação (Mestrado). Instituto Agronômico de Campinas, Campinas.

HELDWEIN, A. B.; BURIOL, G. A.; DALMAGO, G. A.; STRECK, N. A. Variação vertical de temperatura do ar no interior de estufas plásticas. Revista Argentina de Agrometeorologia, v.1, n.1, p.35-42, 2001.

GOMES, E. N. Medidas e Modelos de estimativa da radiação direta na incidência. 2006. 97 p. Tese (Doutorado). Universidade Estadual Paulista, Botucatu.

GUISELINI, C. Microclima na produção de gérbera em ambiente protegido com diferentes tipos de cobertura. 2002. 53 p. Dissertação (Mestrado). Escola Superior de Agricultura "Luis de Queiroz", Universidade de São Paulo, Piracicaba.

GUISELINI, C.; SENTELHAS, P. C.; OLIVEIRA, R. C. Uso de malhas e sombreamento em ambiente protegido II: Efeito sobre a radiação solar global e a fotossinteticamente ativa no crescimento e produção da cultura de pimentão. Revista Brasileira de Agrometeorologia, v.11, p.15-26, 2004.

GUISELINI, C.; SENTELHAS, P. C.; PANDORFI, H.; HOLCMAN, E. Manejo da cobertura de ambientes protegidos: Radiação solar e seus efeitos na produção da gérbera. Revista Brasileira de Engenharia Agrícola e Ambiental, v.14, n.6, p.645-652, 2010.

KITTAS, C.; BAILLE, A.; GIAGLARAS, P. Influence of covering material and shading on the spectral distribution of light in greenhouse. Journal of Agricultural Engineering Research, v.73, p.341-351, 1999.

LEITE, C. A.; ITO, R. M.; LEE, G. T. S.; GANELEVIN, R.; FAGNANI, M. A. Light spectrum management using colored nets to control the growth and blooming of phalaenopsis. Acta Horticulturae, v.770, p.177-184, 2008.

MOREIRA, M. A.; RUDORFFI, B. F. T.; FELÍCIO, J. C.; FREITAS, J. G.; TARGA, M. S. Variação espectral e eficiência do uso da radiação fotossinteticamente ativa em ensaio com genótipos de trigo. Bragantia, v.64, n.3, p.331-338, 2005.

MOTA, C. S.; AMARANTE, C. V. T.; SANTOS, H. P.; ZANARDI, O. Z. Comportamento vegetativo e produtivo de videiras 'Cabernet Sauvignon' cultivadas sob cobertura plástica. Revista Brasileira de Fruticultura, v.30, p.148-153, 2008.

MONTEITH, J. L.; UNSWORTH, M. L. Principles of environmental physics. London: Edward Arnold, 2008.

OLIVEIRA, M. R. V. O emprego de casas de vegetação no Brasil: Vantagens e desvantagens. Pesquisa Agropecuária Brasileira, v.30, n.8, p.1049-1060, 1995.

OLIVEIRA, G. M.; LEITÃO, M. M. V. B. R.; ROCHA, R. C. Temperatura do ar no interior e exterior de ambientes protegidos. Revista Verde de Agroecologia e Desenvolvimento Sustentável, v.7, n.2, p.250-257, 2012. 
PEZZOPANE, J. E. M.; OLIVEIRA, P. C.; REIS, E. F.; LIMA, J. S. S. Alterações microclimáticas causadas pelo uso de tela plástica. Engenharia Agrícola, v.24, n.1, p.9-15, 2004.

REIS, L. S.; Componentes da radiação solar em cultivo de tomate sob condições de ambiente protegido. Revista Brasileira de Engenharia Agrícola e Ambiental, v.16, n.7, p.739-744, 2012.

ROBERTO, S. R.; COLOMBO, L. A.; ASSIS, A. M. de. Revisão: Cultivo Protegido em viticultura. Ciência e Técnica Vitivinícola, v.26, n.1, 2011.

ROMANINI, C. E. B.; GARCIA, A. P.; ALVARADO, L. M.; CAPPELLI, N. L.; UMEZU, C. K. Desenvolvimento e simulação de um sistema avançado de controle ambiental em cultivo protegido. Revista Brasileira de Engenharia Agrícola e Ambiental, v.14, n.11, p.1193-1201, 2010.

SANTOS, L. L.; SEABRA JÚNIOR, S.; NUNES, M. C. M. Luminosidade, temperatura do ar e do solo em ambientes de cultivo protegido. Revista de Ciências Agro-Ambientais, v.8, n.1, p.83- 93, 2010.

SCARANARI, C.; LEAL, P. A. M.; PELLEGRINO, G. Q. Estudo de simulações de microclimas em casas de vegetação visando à aclimatação de mudas micropropagadas de bananeira cv grande naine. Revista Brasileira de Fruticultura, v.30, n.4, p.1001-1008, 2008.

SEEMAN, J. Greenhouse climate. In: SEEMAN, J.; CHIRKOV, Y. I.; LOMAS, J.; PRIMAULT, B. (Eds.). Agrometeorology. New York: Springer-Verlag, 1979. p.167-178.

SENTELHAS, P. C.; SANTOS, A. O. Cultivo Protegido: Aspectos microclimáticos. Revista Brasileira de Horticultura Ornamental, v.1, n.1, p.108-115, 1995.

SILVA, E. T; BYLLARDT, L. V. B.; GOMES, S.; WOLF, G. D. Comportamento da temperatura do ar sob condições de cultivo em ambiente protegido. Revista Acadêmica: Ciências Agrárias e Ambientais, v.1, n.1, p.51-54, 2003.

STEIDLE NETO, A. J; RIBEIRO, A.; ZOLNIE, S; LEITE, F. P. Variabilidade sazonal da relação entre a radiação fotossinteticamente ativa e a radiação global na bacia do Rio Doce, Estado de Minas Gerais. Acta Scientiarum. Agronomy, v.28, n.3, p.427-431, 2006.

ROMANINI, C. E. B.; GARCIA, A. P.; ALVARADO, L. M.; CAPPELLI, N. L. Desenvolvimento e simulação de um sistema avançado de controle ambiental em cultivo protegido. Revista Brasileira de Engenharia Agrícola e Ambiental, v.14, n.11, p.1193-1201, 2010.

VALANDRO, J. ; BURIOL, J. A; ANDRIOLO, J. L.; HELDWEIN, A. B. Transpiração do tomateiro cultivado fora do solo em estufa plástica e sua relação com os elementos meteorológicos. Ciência Rural, v.37, n.6, p.1593-1600, 2007.

VÁSQUEZ, M. A. N; FOLEGATTI, M. V; DIAS, N. S; SILVA, C. R. Efeito do ambiente protegido cultivado com melão sobre os elementos meteorológicos e sua relação com as condições externas. Engenharia Agrícola, v.25, n.1, p.137-143, 2005.

VIDA, J. B.; ZAMBOLIM, L.; TESSMANN, D. J.; BRANDÃO FILHO, J. U. T.; JAQUELINE R., VERZIGNASSI, J. R.; CAIXETA, M. P. Manejo de doenças de plantas em cultivo protegido. Fitopatologia Brasileira, v.29, n.4, p.355-372, 2004. 
VILLELE, O. Le contexte climatic et culture de la serre. 1 - La serre, agent de modificacion du climat. In: L'INRA et les cultures sous serre. Paris: INRA, 1993. p.21-27.

SILVA, B. A.; SILVA, A. R.; PAGIUCA, L. G. Cultivo Protegido: Em busca de mais eficiência produtiva! Revista Técnica Hortifruti Brasil, p.10-18, 2014. Acesso dia 1/06/14 em http://cepea.esalq.usp.br/ hfbrasil/edicoes/132/mat_capa.pdf.

ZHANG, X.; KANG, S.; ZHANG, L.; LIU, J. Spatial variation of climatology monthly crop reference evapotranspiration and sensitivity coefficients in Shiyang river basin of nothwest China. Journal Agricultural Water Management, v.1, n.97, p.1506-1516, 2010.

\section{Histórico}

Submetido em: 31/07/2013

Aceito em: 16/07/2014 